\title{
Evaluation of the carotid artery using wavelet-based analysis of the pulse wave signal
}

\author{
Sameh El-Sharo', Amani Al-Ghraibah², Jamal Al-Nabulsi ${ }^{2}$, Mustafa Muhammad Matalgah ${ }^{3}$ \\ ${ }^{1}$ Jordan Society for Scientific Research, Innovation and Creativity, Amman, Jordan \\ ${ }^{2}$ Department of Medical Engineering, Faculty of Engineering, Al-Ahliyya Amman University, Amman, Jordan \\ ${ }^{3}$ Electrical Engineering Department, Faculty of Engineering, University of Mississippi, Oxford, United States
}

\begin{tabular}{l}
\hline \hline Article Info \\
\hline Article history: \\
Received Oct 18, 2020 \\
Revised Jul 17, 2021 \\
Accepted Aug 14, 2021 \\
\hline
\end{tabular}

Keywords:

Arterial pathologies evaluation Carotid artery

Pulse waveform

Wavelet analysis

\begin{abstract}
The use of pulse wave analysis may assist cardiologists in diagnosing patients with vascular diseases. However, it is not common in clinical practice to interpret and analyze pulse wave data and utilize them to detect the abnormalities of the signal. This paper presents a novel approach to the clinical application of pulse waveform analysis using the wavelet technique by decomposing the normal and pathology signal into many levels. The discrete wavelet transform (DWT) decomposes the carotid arterial pulse wave (CAPW) signal, and the continuous wavelet transform (CWT) creates images of the decomposed signal. The wavelet analysis technique in this work aims to strengthen the medical benefits of the pulse wave. The obtained results show a clear difference between the signal and the images of the arterial pathologies in comparison with normal ones. The certain distinct that were achieved are promising but further improvement may be required in the future.
\end{abstract}

This is an open access article under the CC BY-SA license.

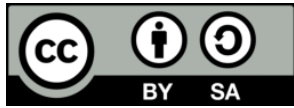

\section{Corresponding Author:}

Amani Al-Ghraibah

Department of Medical Engineering, Al-Ahliyya Amman University

Amman, Jordan

Email: a.ghraibah@ammanu.edu.jo

\section{INTRODUCTION}

Pulse wave embeds useful information about human health in general and the cardiovascular system in particular. Palpation of the pulse waves assesses some pathologies, which has, since antiquity, been one of the tools in medicine. Mahomed, established the foundation of pulse wave analysis in a short medical lifetime from 1872 to 1884 [1]-[3]. In 1872, he described the normal radial pressure and carotid waveforms and showed the differences between them. He also illustrated the differences between hypertension and chronic nephritis in [1]. Furthermore, he described the effects of arterial degeneration with ageing on the arterial pulse [2], [3]. Real-time recordings of the pulse waveform, referred to as sphygmography, had been well investigated in medical literature and used to describe heart block, hypertension, and other pathological conditions in addition to the effects of anti-anginal drugs [4]. Interest in pulse wave methodology had declined in the period of first half of the last century but has recently been revived with the introduction of computers technology in modern recording instrumentation. The introduction of new high-tech computing methods allowed for more accurate recordings and analyses of pulse waves in various parts of the vascular system, taking into consideration that pulse wave analysis is non-invasive, simple, and with apparent sensitivity [5]-[7]. Obtained pulse waveforms provide cardiologists with valuable information about the morphological structure and health state of the corresponding blood vessel. This type of information can be further enhanced by using different analysis tools; mathematical and computational [8], [9]. Recent clinical studies shown that pulse waveform analysis can help in the diagnosis of several vascular diseases such as arterial stiffness and its development with aging, which is considered as one of the most cardiovascular risk factors that may lead to premature death [10], [11]. Several 
analysis methods have been proposed in literature for extracting specific useful information from pulse wave signals. These methods include the pulse waveform analysis, Fourier and Wavelet techniques, and pulse wave imaging methods were used to investigate the cross-sectional relationship between periodontal status and arterial stiffness [12]. The amplitude parameters of the pulse in the time domain give a good indication of the left ventricular ejection function and cardiac output [13]. The frequency domain method was also used to analyze the aortic impedance, which is the relationship between pulsatile pressure and flow in the aorta. This phenomenon was well-addressed by McDonald in [14] on the basis of wave reflection. Transfer functions were introduced to characterize properties of vascular beds in the frequency domain, and the validity of linearity assumption in the arterial tree were also established in [14], [15].

Wavelet transform became a point of interest technique in the medical-related studies especially in biomedical engineering as early as 1990s (see e.g., [16]-[19]). This is motivated by its ability of detecting and analyzing important features of the signals, which could not be easily revealed in time-domain, in order to understand or model physiological systems [20]. Wavelet transform allows complex information in the signals and patterns to be decomposed into simple forms at different positions and scales and consequently reconstructed with high precision. Wavelet transform of a function is the enhanced version of Fourier transform, where the Fourier transform is a powerful tool in analyzing the components of a stationary signal. But it is failed for analyzing the non-stationary signal whereas wavelet transform allows the components of a non-stationary signal to be analyzed. Another important advantage of wavelet transform in comparison with the other signal analysis methods is that it can detect and analyze abrupt changes in signals [21]. To the best of our knowledge, analyzing carotid arterial pulse wave (CAPW) signal using discrete wavelet transform (DWT) and continuous wavelet transform (CWT) has not been reported widely in literature. In this paper, we consider pulse wave signals obtained from the carotid artery for different cardiovascular pathologies such as the cardiac failure, arteriosclerosis, and hypertension [22], [23] and develop an analysis framework based on the DWT and CWT. The wavelet analysis technique presented in this paper is presented to strengthen the medical benefits of the pulse wave signal when analyzed in new dimensions of the wavelet transforms.

The main contribution of this paper is to create a fast-automated diagnosis method that helps physicians in decision making process as applied to the arterial pulse signal condition whether it is normal or abnormal using both the discrete and continuous wavelet analyses. The DWT decomposes the CAPW signal into approximate and details components that reveal hidden information which cannot be observed in the timedomain CAPW signal, while the CWT creates a 3D surface and contour images that reveal other types of information in the time-scale domain. The proposed technique is a novel addition to the medical diagnosis processes as the abnormality of the CAPW can be noticed faster and easier than the conventional diagnosis processes. Comparisons between the normal and the abnormal CAPW signals are discussed after applying the proposed system. Furthermore, differences in characteristics between different types of abnormal CAPW signals could also be easily distinguished. The remainder of the paper is organized as follows: methods of the analysis are presented in section 2 . In section 3, the results and discussion are included, and finally section 4 concluded the main idea of this work.

\section{METHOD}

Wavelet analysis can be used as a mathematical tool to extract hidden information from different types of data such as audio signals and images that are not obvious from their time-domain representations. Sets of wavelets are generally needed to analyze data entirely. A set of "complementary" wavelets will decompose data without gaps or overlap so that the decomposition process is mathematically reversible [24]-[27]. In this paper, we use the well-known "Daubechies" wavelets (with ten levels of decomposition) to analyze CAPW signals.

\subsection{Discrete wavelet transform (DWT)}

Using DWT, the CAPW signal is decomposed into N levels using DWT, where N must be a strictly positive integer chosen to be ten levels in this paper as many trials were done at different levels starting from 5 levels to 13 levels, but ten levels gave the best results. In the first step of the DWT-based analysis, the DWT of the arterial signal $s(t)$ produces two sets of coefficients: approximation coefficients cA1, and detail coefficients cD1. These vectors are obtained by convolving the signal s with the low-pass filter Lo_D for approximation, and with the high-pass filter Hi_D for detail, followed by dyadic decimation (down sampling) as shown in the block diagram in Figure 1, where the length of each filter is equal to $2 \mathrm{~N}$ [28]. The next step splits the approximation coefficients cA1 into two parts following same scheme in the first step by replacing $\mathrm{s}$ by $\mathrm{cA} 1$, and hence producing $\mathrm{cA} 2$ and $\mathrm{cD} 2$; and steps continue as such $\mathrm{N}$ times. Following these steps, the wavelet decomposition of the arterial signal s (analyzed at level $\mathrm{N}=10$ ) results in the structure: [cA10, cD10, ..., cD1] as shown in Figure 2. Throughout the remaining parts of the paper, we create explanation plots of the reconstructed approximate and details signals for normal as well as 4 cases of abnormal CAPW signals. 


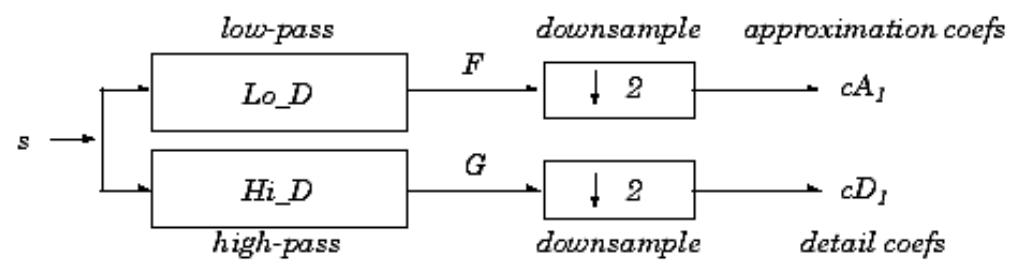

Figure 1. The first step of DWT

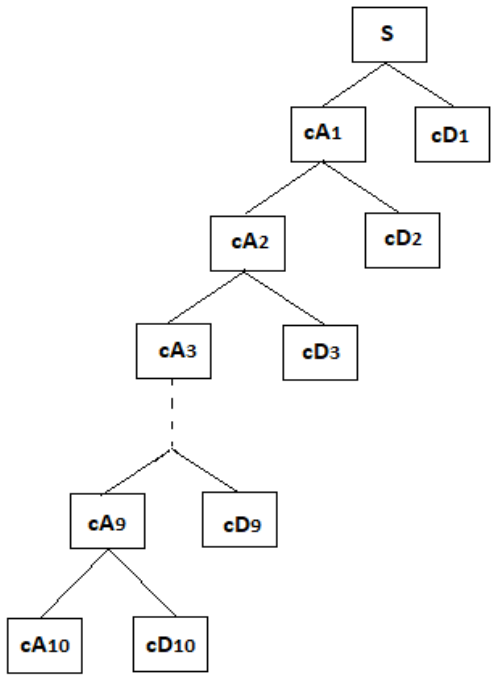

Figure 2. The general structure of DWT of 10 levels

\subsection{Continuous wavelet transform}

Besides the DWT, the CWT is another method that decomposes the CAPW signal into time-shifted scaled basis functions (i.e., wavelets). The CWT is a tool that offers an over-complete representation of a signal by allowing the translation and scale parameter of the wavelets vary continuously [29]. The CWT, of the arterial signal $s(t)$ at a scale and translational value $b$ is expressed by the integral.

$$
X_{w}(a, b)=\frac{1}{\sqrt{\mathrm{I} a \mathrm{I}}} \int_{-\infty}^{\infty} s(t) \bar{\psi}\left(\frac{t-b}{a}\right) d t
$$

Where $\bar{\psi}(\mathrm{t})$ is a continuous function in both time and frequency domains called the mother wavelet and the over bar $(\bar{\psi})$ denotes the complex conjugate. The main purpose of the mother wavelet is to provide a source function to create different daughter wavelets for different $b$ and $a$ parameters, which are simply the translated and scaled versions of the mother wavelet. CWT has shown effective capabilities in determining the damping ratio of oscillating signals (e.g., identification of damping in dynamic systems) and robust resistance to the noise embedded in the signal [29], [30]. The output after CWT decomposition is the real matrix $X_{W}$ using the wavelet type "Daubechies". The results are interpreted using 3D surface and contour plots representations for CAPW signals under study in this paper. The contour and 3D plots technically include same information; however, weak peaks that might be hidden between large peaks in $3 \mathrm{D}$ plots can be easily seen in a contour plot.

\subsection{CAPW signals decomposition}

A normal CAPW of a healthy person is represented by a number of piecewise continuous functions over the pulse cycle period [31] and plotted using MATLAB simulation shown in Figure 3(a). Similarly, CAPWs of four different states of pathology are shown in Figures 3(b)-(e) which also plotted using MATLAB software with the reference of the pathological signals found in literature [32]. To make it easy to understand the signals abnormality, they are described by the following sentences: Figure 3(b) is a CAPW with large and bounding pulses, Figure 3(c) is a CAPW with small and week pulses, Figure 3(d) is a CAPW signal with free dicrotic notch, and Figure 3(e) is a CAPW signal with flat dicrotic notch [32]. 


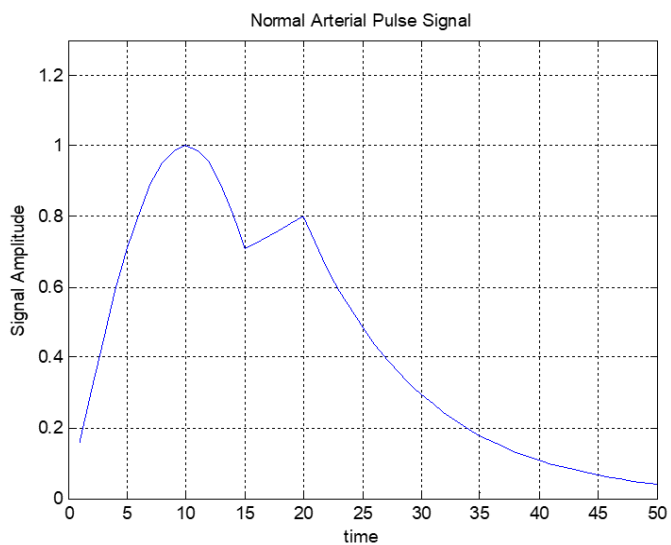

(a)

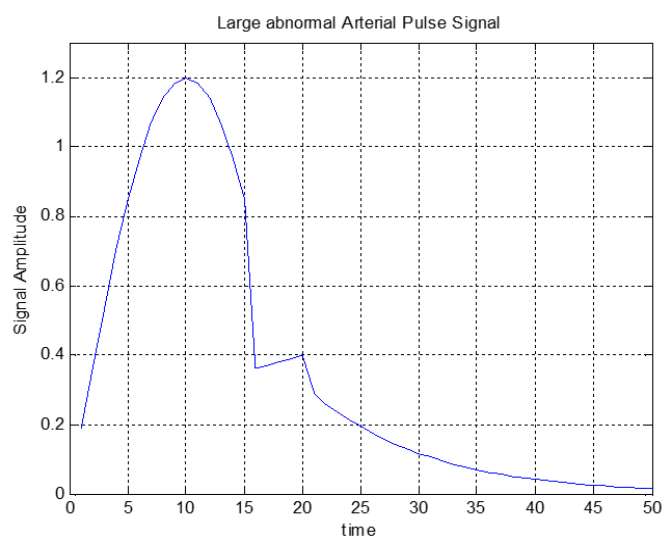

(c)

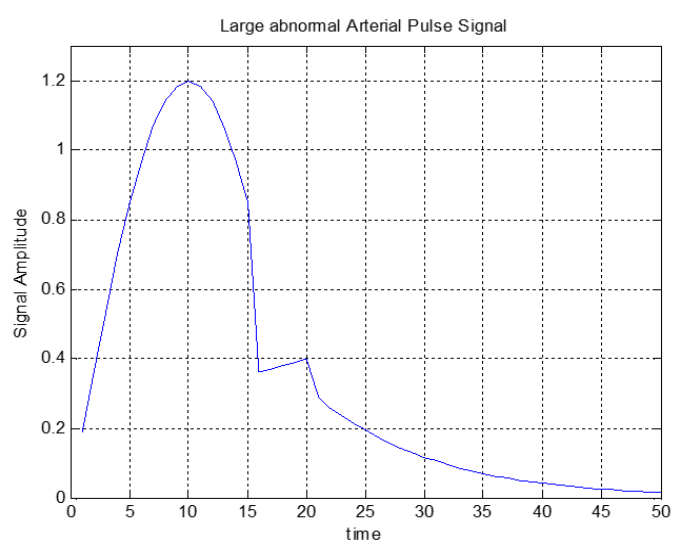

(b)

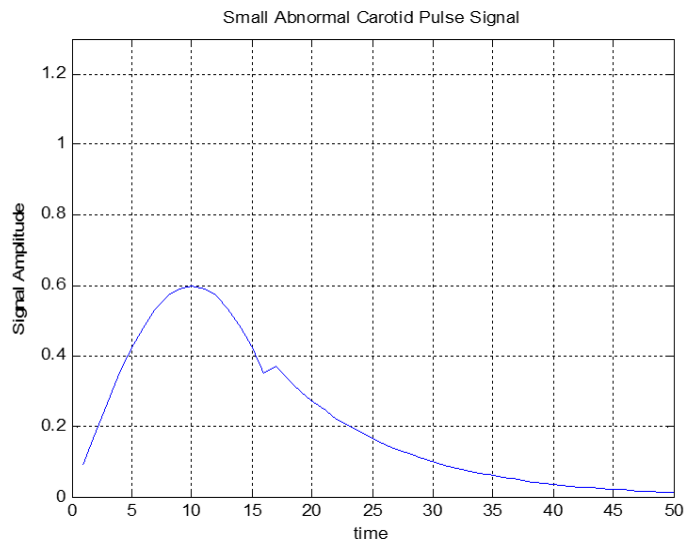

(d)

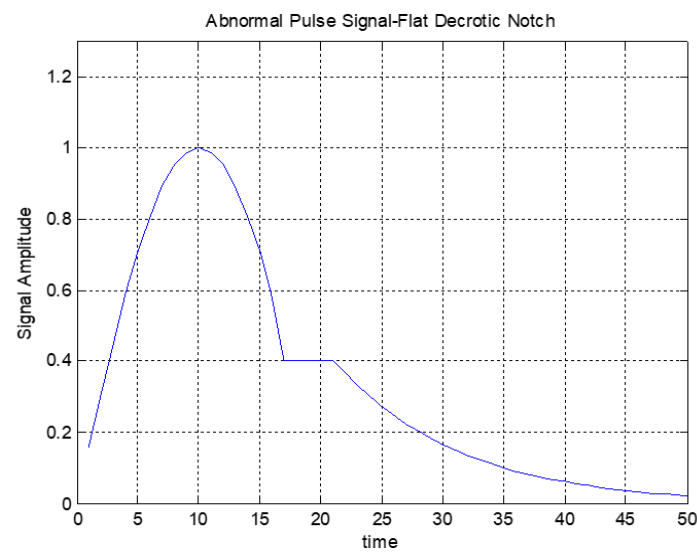

(e)

Figure 3. CAPW signals of normal and 4 pathology cases, (a) normal CAPW signal, (b) CAPW with large and bounding pulses, (c) CAPW with small and week pulses, (d) CAPW with free dicrotic notch, and

(e) CAPW with flat dicrotic notch

To make use of the indicated up CAPW signals in this work, we reconstructed them based on the wavelet decomposition structure created in the decomposition step. Figure 4 presents the reconstructed CAPW signals, using the 3D approximation reconstruction at ten decomposition levels, and time duration of $50 \mathrm{~ms}$. Figure 4(a) is the normal CAPW signal, Figures 4(b) and 4(c) show the CAPW with large and bounding pulses, and CAPW with small and week pulses, respectively. Figures 4(d) represents the CAPW with free dicrotic notch and Figures 4(e) is the CAPW with flat dicrotic notch. This time is chosen because the mean delay of the first and second carotid arterial sound after aortic valve opening and closer is $43+/-6 \mathrm{~ms}$ and $43+/-7 \mathrm{~ms}$, respectively. 


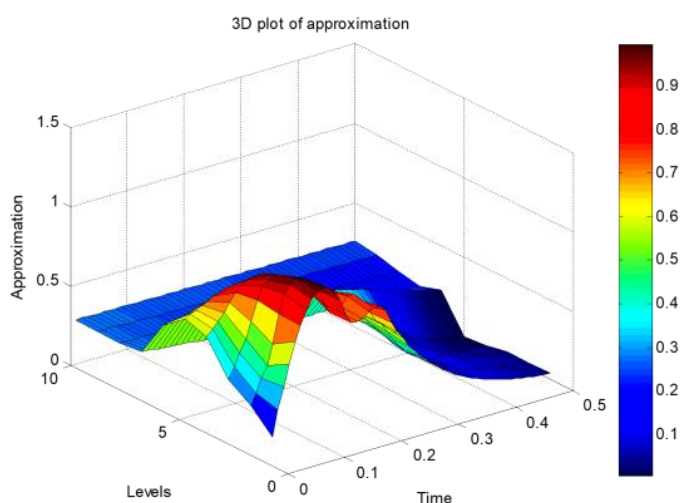

(a)

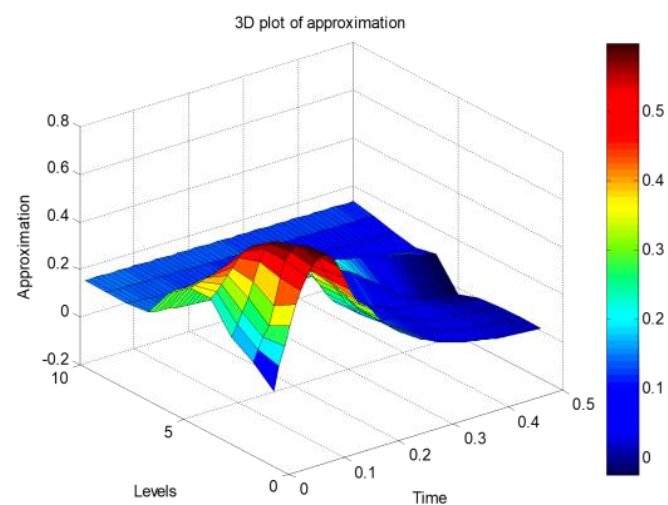

(c)

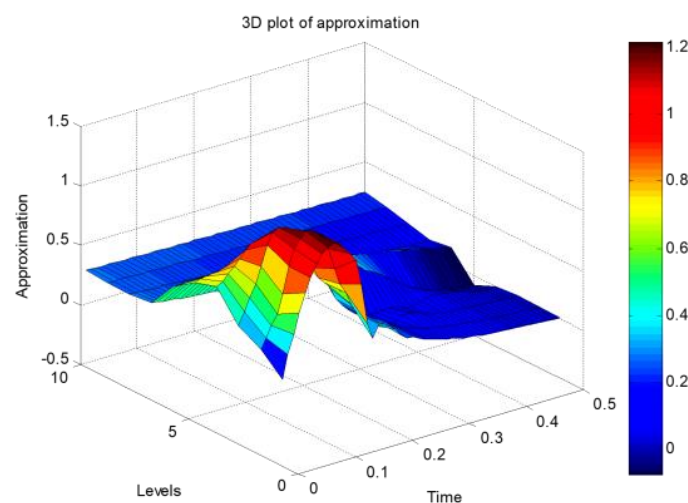

(b)

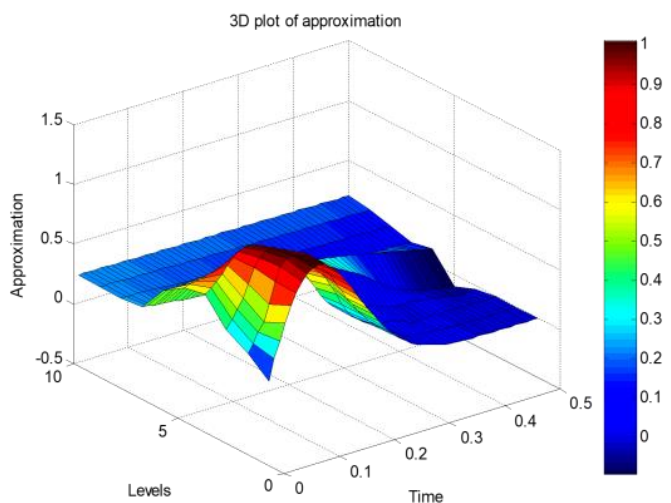

(d)

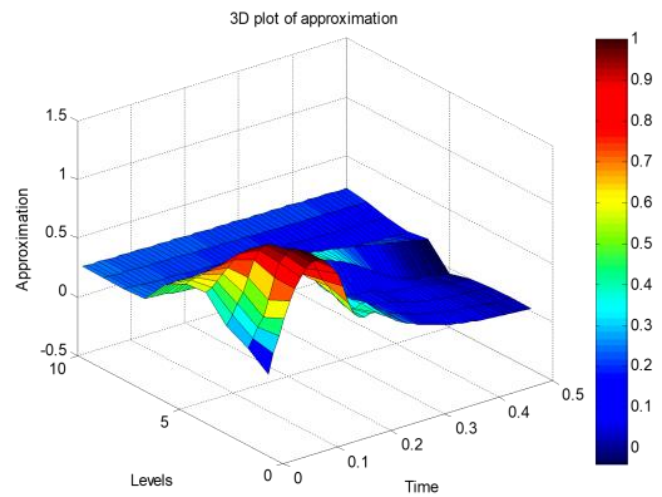

(e)

Figure 4. 3D approximation reconstructions of the CAPW signals, (a) normal CAPW signal, (b) CAPW with large and bounding pulses, (c) CAPW with small and week pulses, (d) CAPW with free dicrotic notch, and

(e) CAPW with flat dicrotic notch

Figure 5 shows the details reconstruction at the same levels and time duration. Figure 5(a) shows the normal CAPW signal, while Figures 5(b) and 5(c) show the CAPW with large and bounding pulses and CAPW with small and week pulses, respectively. Figure 5(d) is the CAPW with free dicrotic notch, and Figure 5(e) is the CAPW with flat dicrotic notch. The contour of approximation and the contour of details are given in Figures 6 where Figure 6(a) is the normal CAPW signal. Figures 6(b) and 6(c) shows the CAPW with large and bounding pulses and CAPW with small and week pulses, respectively. On the other hand, Figures 6(d) and 6(e) are the CAPW with free dicrotic notch, and CAPW with flat dicrotic notch, respectively. Moreover, the contour of details are given in Figure 7, where Figure 7(a) shows the normal CAPW signal, and Figures 7(b) and 7(c) are the contour of the CAPW with large and bounding pulses and CAPW with small and week pulses, respectively. While Figures 7(d) and 7(e) are the CAPW with free dicrotic notch, and CAPW with flat dicrotic 
notch, respectively. Figure 8 (see in appendix) is the CWT of studied CAPW signals, where contour plots are shown on the left sub-figures, and 3D surface plots with scale versus time in the right sub-figures. Figure 8(a) shows the Normal CAPW signal, where Figures 8(b) and 8(c) are for CAPW with large and bounding pulses and for CAPW with small and week pulses, respectively. Figures 8(d) and 8(e) are for the CAPW with free dicrotic notch, and the CAPW with flat dicrotic notch, respectively. These plots help physicians to decide if the recorded CAPW signal of the patient is normal or has a particular pathology by comparison among these images as will be discussed in the sequel. Also, further researches could be done by investigating features from the resultant images and use the extracted features to classify the input signal as normal or pathology signals using an automated classification system.

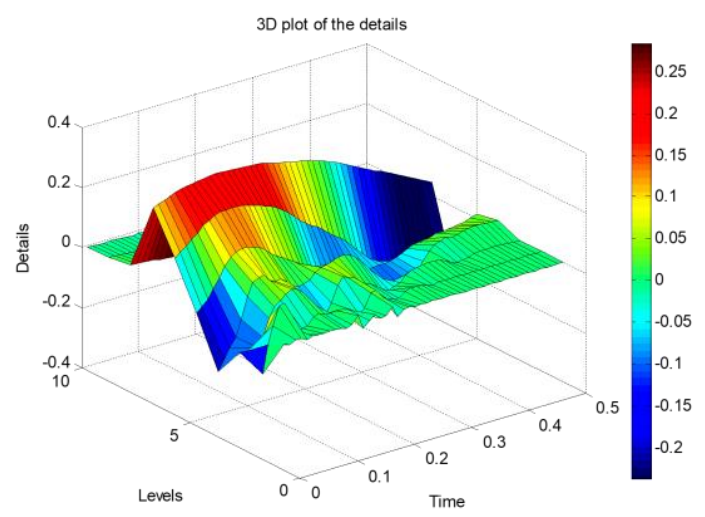

(a)

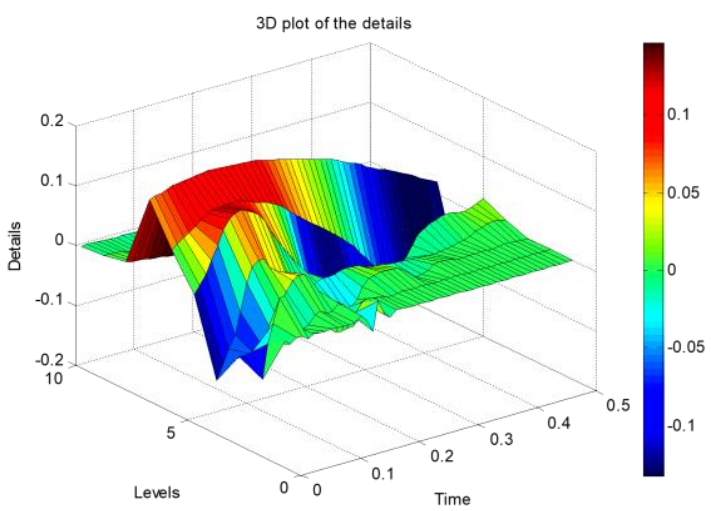

(c)

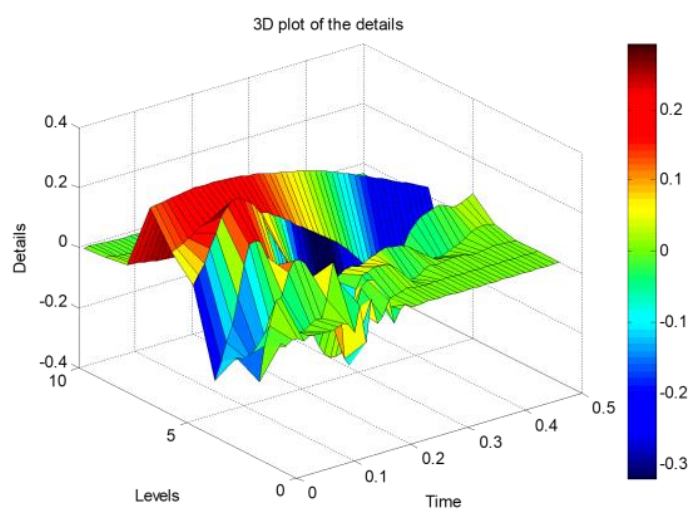

(b)

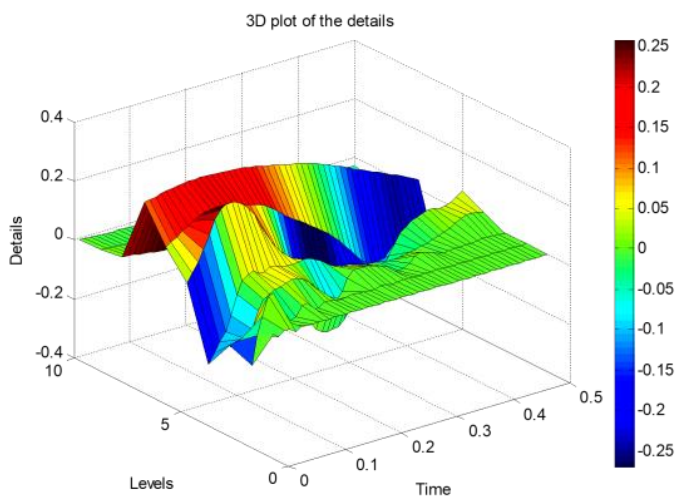

(d)

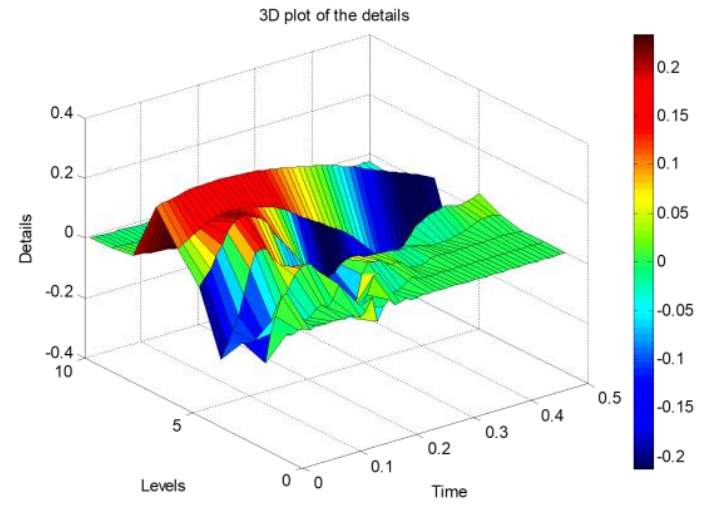

(e)

Figure 5. 3D details reconstructions of the CAPW signals, (a) normal CAPW signal, (b) CAPW with large and bounding pulses, (c) CAPW with small and week pulses, (d) CAPW with free dicrotic notch, and

(e) CAPW with flat dicrotic notch 


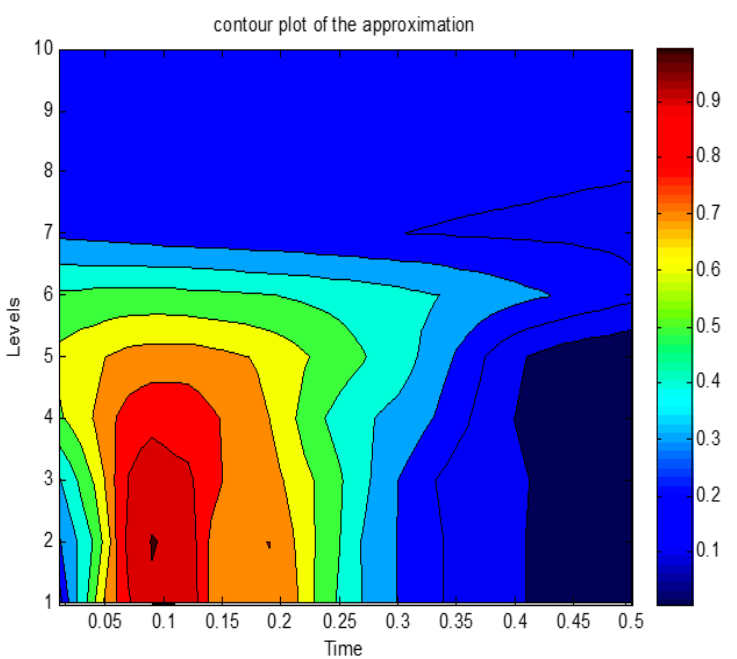

(a)

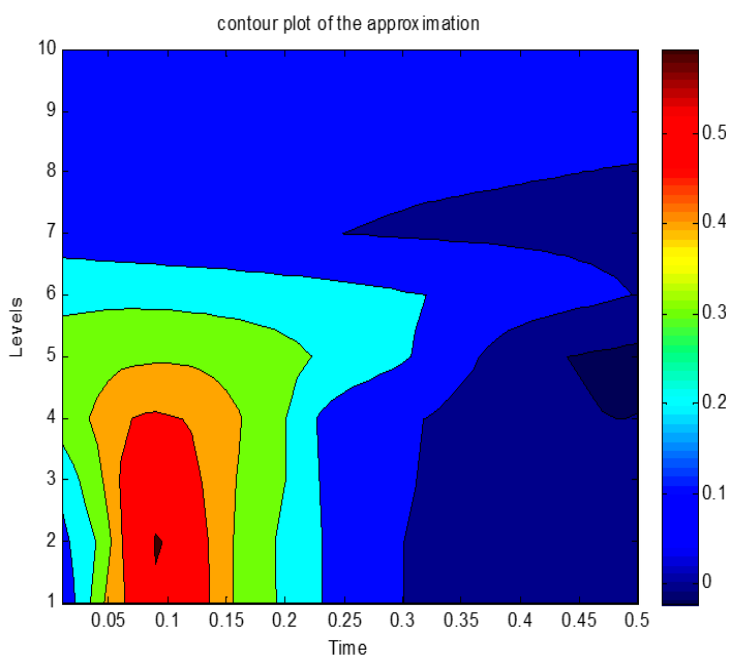

(c)

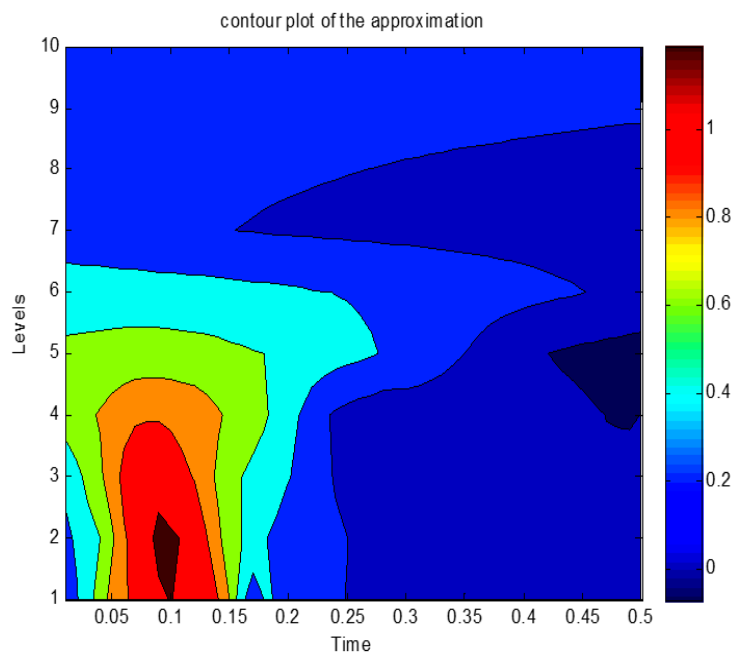

(b)

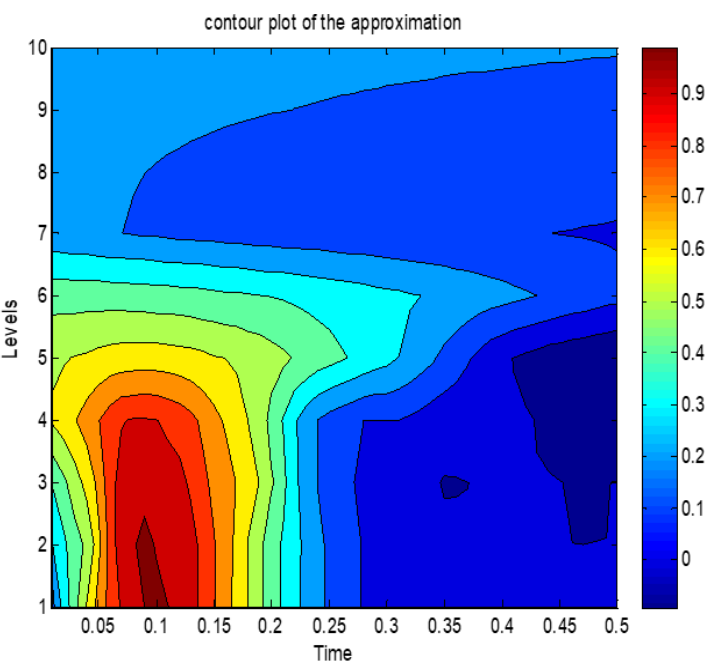

(d)

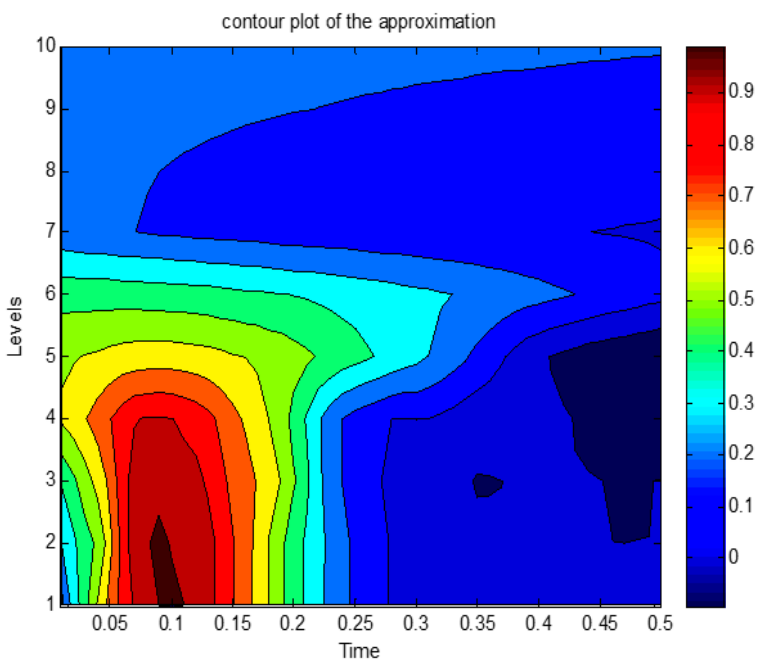

(e)

Figure 6. The contour of approximation of CAPW signals, (a) normal CAPW signal, (b) CAPW with large and bounding pulses, (c) CAPW with small and week pulses, (d) CAPW with free dicrotic notch, and (e) CAPW with flat dicrotic notch 


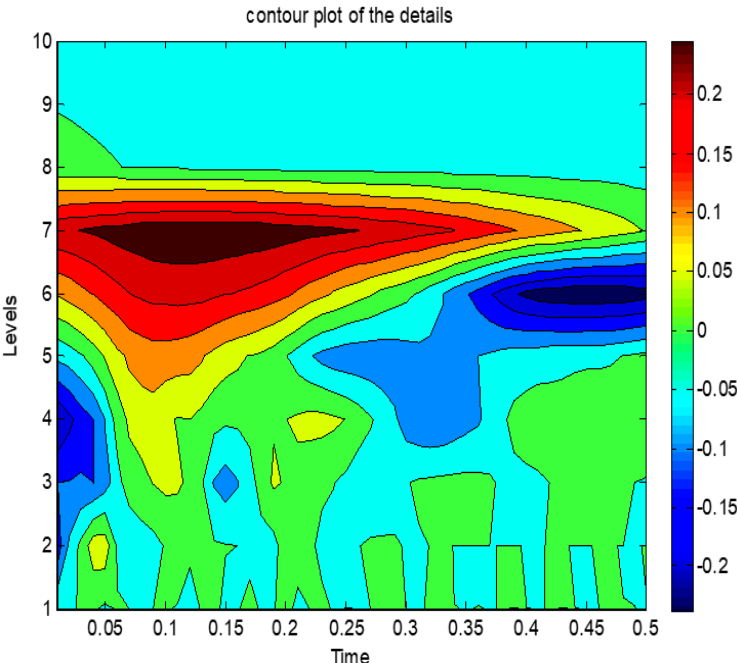

(a)

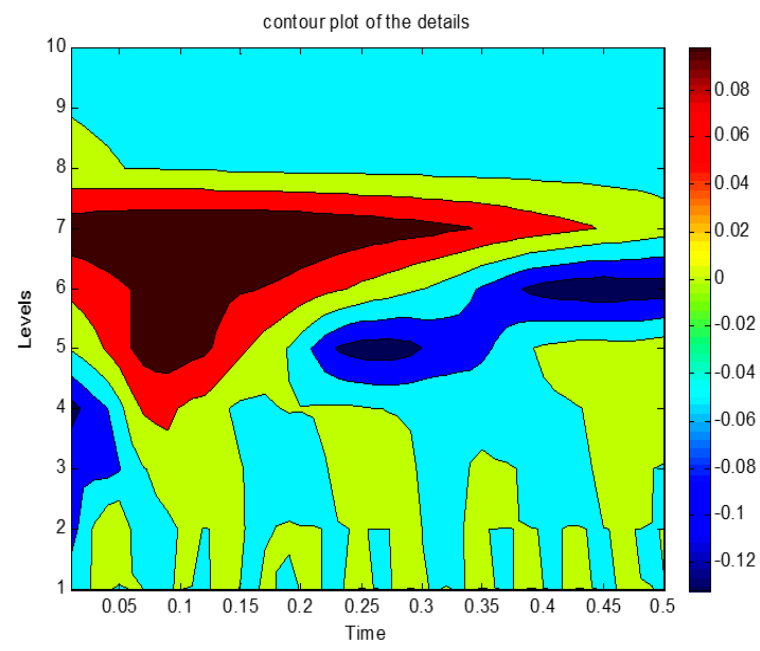

(c)

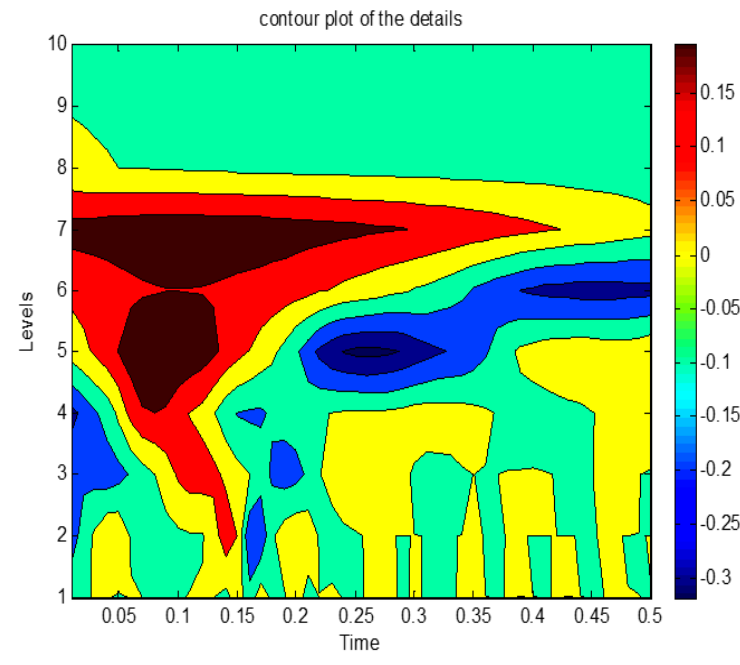

(b)

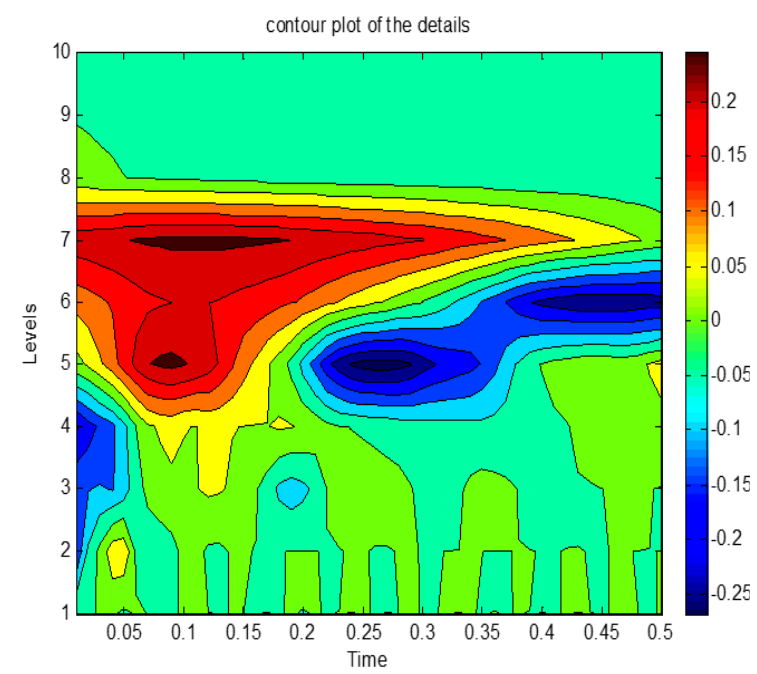

(d)

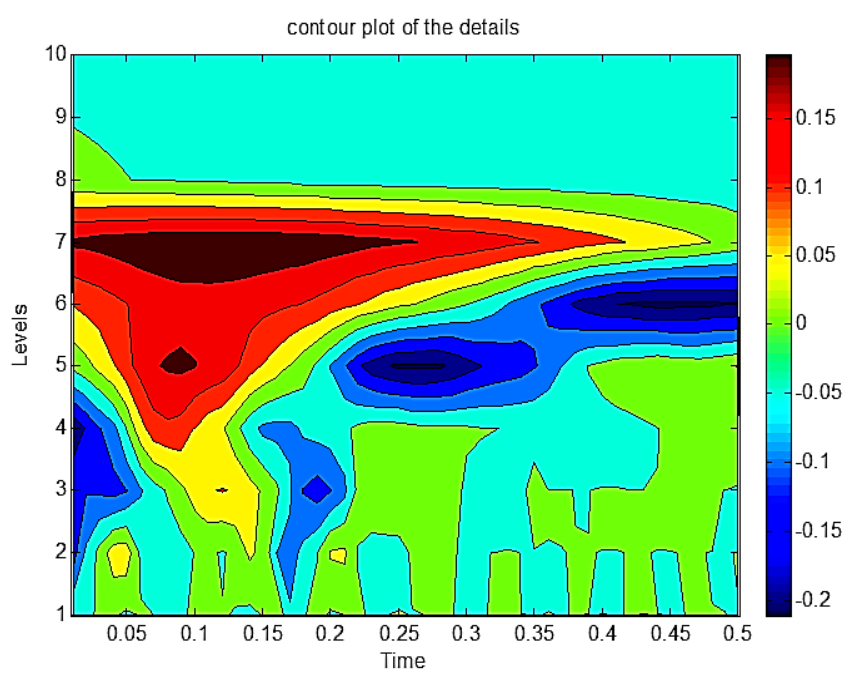

(e)

Figure 7. The contour of details of CAPW signals, (a) normal CAPW signal, (b) CAPW with large and bounding pulses, (c) CAPW with small and week pulses, (d) CAPW with free dicrotic notch, and (e) CAPW with flat dicrotic notch 


\section{RESULTS AND DISCUSSION}

To show the diagnostic merit of the proposed method, four different abnormal arterial pulse signals are studied and decomposed using DWT and CWT. A software system using MATLAB is built to find the difference between the normal and abnormal CAPW. In this section, comparisons between the normal and the abnormal CAPW signals after applying the proposed system are summarized at the end of each subsection below.

\subsection{CAPW signal with large and bounding pulses}

One of the abnormal CAPW signals studied is the one with large and bounding pulse due to vasodilatation; this signal is shown in Figure 3(b). It represents some pathologies like bradycardia, heart block, and atherosclerosis. It is characterized by amplitude larger than the normal signal seen in Figure 3(a). Figures 4(b) and 5(b) show the approximation and details reconstruction respectively, after the DWT of this signal, comparing this case with the normal one Figure 4(a) and 5(a), it is clear that there is an obvious difference between them, the approximation curve Figure 4(b) has larger amplitude range, while the details curve Figure 5(b) is not flat and has many peaks more than the normal curve. The contour plots of the approximation and details are shown in Figures 6(b) and 7(b) respectively, the plots show that the dark areas in the middle are wider and more complicated than the contour plot of the normal signal as seen in Figures 6(a) and 7(a). Same conclusion can also be derived by performing the CWT of this large and bounding signal where the obtained result is shown in Figure 8(b). The comparison of this outcome with that of the normal plot in Figure 8(a) reveals obvious differences between them where the small peak that appears in middle between the two strong peaks that was apparent in the normal CAPW case disappears in the abnormal case.

\subsection{CAPW signal with small and week pulses}

The second abnormal signal studied in this paper is a CAPW with small and week dicrotic notch, which may indicate a situation of heart failure and severe aortic stenosis. Here the signal's amplitude is smaller than the normal signal due to vasoconstriction, this signal is shown in Figure 3(c). Applying the DWT on this signal, similarly to previous cases, plots in Figures 4(c) and 5(c) are obtained. It is seen that there are some differences between these plots and those for the normal CAPW or the long and bounding signal, specifically, Figure 4(c) has lower amplitude range, while the details curve Figure 5 (c) is not smooth and has more peaks than the normal curve. Figure 6(c) and 7(c) show the approximation and details contours, they have an obvious difference than the contour of the normal CAPW signal. In contrary, the CWT of this week signal presented in Figure $8(\mathrm{c})$ has two ovals with wide and thin shapes which have small dissimilarity than normal images shown in Figure 8(a).

\subsection{CAPW signal with free dicrotic notch}

The third abnormal case studied is the cardiac failure characterized by a CAPW signal with free dicrotic notch depicted in Figure 3(d). The consequence of this distortion leads to a dramatic change in the corresponding DWT results presents in Figure 4(d) and 5(d). The approximation and details contour plots also have a big difference than the normal contour as seen in Figures 6(d) and 7(d) where the dark areas are larger and spread over the plot compared with Figures 6(a) and 7(a). The CWT of this abnormal signal is presented in Figure 8(d) has two ovals with thinner and wider shapes than normal images which is considered as a large difference between them and the normal images in Figure 8(a).

\subsection{CAPW signal with flat dicrotic notch}

Another abnormality of the cardiovascular system, the hypertension with CAPW signal that is characterized by a flat dicrotic notch as seen in Figure 3(e). After executing DWT on this signal, the same way as previous signals, a corresponding group of signals is obtained Figure 4(e) and 5(e). Comparing transformed signals of this abnormal signal with those of the normal pulse signal, some differences between these contours are derived as it has thinner curve while the amplitude is close to the normal. Figures 6(e) and 7(e) also present a large variation in the colors than the normal contour and the peaks are close to each other. The CWT of this abnormal signal is depicted in Figure 8(e) and there is a slightly dissimilar between it and the normal images shown in Figure 8(a). Table 1 summarizes the obtained results as detected from Figures 4 to 8 . The proposed technique is a novel addition to the medical diagnosis processes as the abnormality of the CAPW is now noticed faster and easier than the conventional diagnosis processes. The proposed system helps researchers as it provides a new comparison method to compare between the normal and the abnormal CAPW signals. Also, the differences in characteristics between the different types of the abnormal CAPW signals become easily distinguished as well. 
Table 1. Summary of the obtained results as detected from Figures 4 to 8

\begin{tabular}{|c|c|c|c|c|c|c|}
\hline & \multicolumn{2}{|c|}{ Features in DWT Signals } & \multicolumn{2}{|c|}{ Features in DWT contour plots } & \multicolumn{2}{|c|}{$\begin{array}{l}\text { Features in CWT 3D plots and } \\
\text { its contour }\end{array}$} \\
\hline & $\begin{array}{l}\text { Approximation } \\
\text { 3D plots }\end{array}$ & $\begin{array}{l}\text { Details } \\
\text { 3D plots }\end{array}$ & $\begin{array}{l}\text { Approximation } \\
\text { contours }\end{array}$ & $\begin{array}{l}\text { Details } \\
\text { contours }\end{array}$ & contour & 3D plots \\
\hline $\begin{array}{l}\text { Normal } \\
\text { CAPW }\end{array}$ & $\begin{array}{l}\text { Amplitude is in the } \\
\text { range } \\
{[0,1] \text { and the shape }} \\
\text { is almost rough. }\end{array}$ & $\begin{array}{l}\text { Amplitude is } \\
\text { in the range } \\
{[-0.2,0.2] \text { and }} \\
\text { one sharp } \\
\text { peak with flat } \\
\text { curve }\end{array}$ & $\begin{array}{l}\text { Large number of } \\
\text { colors degrades } \\
\text { (11 colors) and } \\
\text { peaks are close to } \\
\text { each other }\end{array}$ & $\begin{array}{l}\text { Large number } \\
\text { of colors } \\
\text { degrades (11 } \\
\text { colors) and } 2 \\
\text { thin oval shapes }\end{array}$ & $\begin{array}{l}\text { Two ovals } \\
\text { with wide } \\
\text { and thin } \\
\text { shapes }\end{array}$ & $\begin{array}{c}\text { Amplitude } \\
\text { range } \\
{[-2,2.5]} \\
3 \text { peaks at the } \\
\text { bottom }\end{array}$ \\
\hline $\begin{array}{l}\text { CAPW } \\
\text { With }\end{array}$ & $\begin{array}{l}\text { Amplitude is in the } \\
\text { range }[0,1.2] \text { and the }\end{array}$ & $\begin{array}{l}\text { Amplitude is } \\
\text { in the range }\end{array}$ & $\begin{array}{l}\text { Small number of } \\
\text { colors degrades }\end{array}$ & $\begin{array}{l}\text { Small number } \\
\text { of colors }\end{array}$ & $\begin{array}{l}\text { Two ovals } \\
\text { with }\end{array}$ & $\begin{array}{l}\text { Amplitude } \\
\text { range }\end{array}$ \\
\hline $\begin{array}{l}\text { Large and } \\
\text { Bounding } \\
\text { Pulses }\end{array}$ & $\begin{array}{c}\text { shape is narrow and } \\
\text { smoother than } \\
\text { normal signal }\end{array}$ & $\begin{array}{c}{[-0.3,0.3] \text { and }} \\
\text { not flat curve } \\
\text { with more } \\
\text { peaks }\end{array}$ & $\begin{array}{c}\text { (8 colors) and } \\
\text { peaks are far from } \\
\text { each other }\end{array}$ & $\begin{array}{l}\text { degrades }(7 \\
\text { colors) and } 3 \\
\text { wide oval } \\
\text { shapes }\end{array}$ & $\begin{array}{c}\text { thinner } \\
\text { shapes than } \\
\text { normal }\end{array}$ & $\begin{array}{c}{[-1.5,2.5] \text { and } 2} \\
\text { peaks at the } \\
\text { bottom }\end{array}$ \\
\hline $\begin{array}{l}\text { CAPW } \\
\text { With }\end{array}$ & $\begin{array}{l}\text { Amplitude is in the } \\
\text { range }\end{array}$ & $\begin{array}{l}\text { Amplitude is } \\
\text { in the range }\end{array}$ & $\begin{array}{l}\text { Small number of } \\
\text { colors degrades }\end{array}$ & $\begin{array}{l}\text { Small number } \\
\text { of colors }\end{array}$ & $\begin{array}{l}\text { Two ovals } \\
\text { with wide }\end{array}$ & $\begin{array}{l}\text { Amplitude } \\
\text { range }\end{array}$ \\
\hline $\begin{array}{l}\text { Small and } \\
\text { Week } \\
\text { Pulses }\end{array}$ & $\begin{array}{c}{[0,0.6] \text { and the }} \\
\text { shape is narrow and } \\
\text { smoother than } \\
\text { normal signal }\end{array}$ & $\begin{array}{c}{[-0.1,0.1] \text { and }} \\
\text { not flat curve } \\
\text { with more } \\
\text { peaks }\end{array}$ & $\begin{array}{c}\text { (8 colors }) \text { and } \\
\text { peaks are far from } \\
\text { each other }\end{array}$ & $\begin{array}{l}\text { degrades }(6 \\
\text { colors) and } 3 \\
\text { wide oval } \\
\text { shapes }\end{array}$ & $\begin{array}{c}\text { and thinner } \\
\text { shapes than } \\
\text { normal }\end{array}$ & $\begin{array}{l}{[-0.8,1.3] \text { and } 2} \\
\text { peaks at the } \\
\text { bottom }\end{array}$ \\
\hline $\begin{array}{l}\text { CAPW } \\
\text { With Free } \\
\text { dicrotic } \\
\text { Notch }\end{array}$ & $\begin{array}{l}\text { Amplitude is in the } \\
\text { range }[0,1] \text { and the } \\
\text { shape is wider and } \\
\text { smoother the normal } \\
\text { signal }\end{array}$ & $\begin{array}{l}\text { Amplitude is } \\
\text { in the range } \\
{[-0.2,0.2] \text { and }} \\
\text { not flat curve } \\
\text { with one peak }\end{array}$ & $\begin{array}{l}\text { Large number of } \\
\text { colors degrades } \\
\text { (12 colors) and } \\
\text { peaks are closer to } \\
\text { each other }\end{array}$ & $\begin{array}{l}\text { Large number } \\
\text { of colors } \\
\text { degrades (12 } \\
\text { colors) and } 3 \\
\text { thin oval shapes }\end{array}$ & $\begin{array}{l}\text { Two ovals } \\
\text { with } \\
\text { thinner and } \\
\text { wider } \\
\text { shapes }\end{array}$ & $\begin{array}{c}\text { Amplitude } \\
\text { range } \\
{[-0.8,1.3] \text { and } 2} \\
\text { peaks at the } \\
\text { bottom }\end{array}$ \\
\hline $\begin{array}{l}\text { CAPW } \\
\text { With Flat } \\
\text { dicrotic } \\
\text { Notch }\end{array}$ & $\begin{array}{l}\text { Amplitude is in } \\
\text { range }[0,1] \text { and the } \\
\text { shape is thinner and } \\
\text { smoother than } \\
\text { normal signal }\end{array}$ & $\begin{array}{l}\text { Amplitude is } \\
\text { in the range } \\
{[-0.2,0.2] \text { and }} \\
\text { not flat curve } \\
\text { with one peak }\end{array}$ & $\begin{array}{l}\text { Large number of } \\
\text { colors degrades } \\
\text { (12 colors) and } \\
\text { peaks are closer to } \\
\text { each other }\end{array}$ & $\begin{array}{l}\text { Large number } \\
\text { of colors } \\
\text { degrades ( } 10 \\
\text { colors) and } 3 \\
\text { thin oval shapes }\end{array}$ & $\begin{array}{l}\text { Two ovals } \\
\text { with wide } \\
\text { and thinner } \\
\text { shapes than } \\
\text { normal } \\
\end{array}$ & $\begin{array}{l}\text { Amplitude } \\
\text { range } \\
{[-2,2] \text { and } 2} \\
\text { peaks at the } \\
\text { bottom }\end{array}$ \\
\hline
\end{tabular}

\section{CONCLUSION}

This study found new concept of using wavelet technique to analyze different forms of arterial pulse wave signal and to augment medical information embedded in the carotid pulse. It was seen from the discussion how this method is capable of differentiating different forms of the analyzed signal which reflects different pathological cases of the carotid artery. This method can be enriched by extracting numerical values from the obtained images such as the amplitude and number of peaks and valleys for each case. It is worth to say that this study can be extended to analyze the pulse wave of other arteries like the radial and femoral arteries.

\section{APPENDIX}
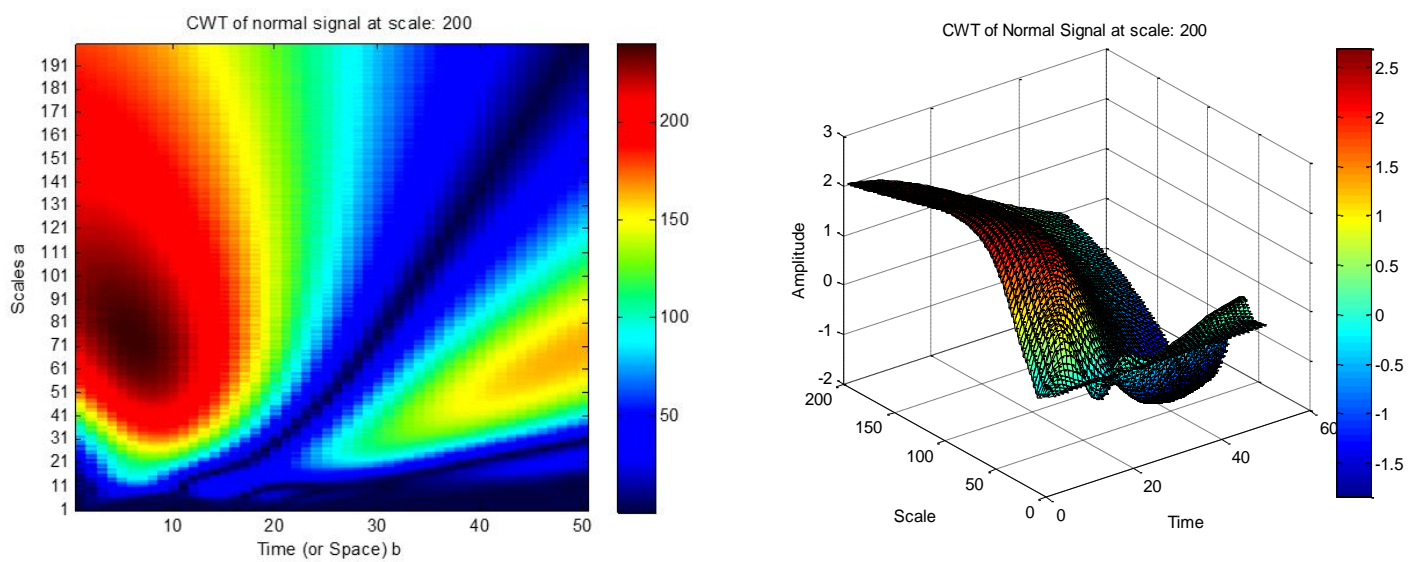

(a)

Figure 8. Contour plots (left sub-figures) and 3D surface plot (right sub-figures), (a) Normal CAPW signal, (b) CAPW with large and bounding pulses, (c) CAPW with small and week pulses, (d) CAPW with free dicrotic notch, and (e) CAPW with flat dicrotic notch (continue) 

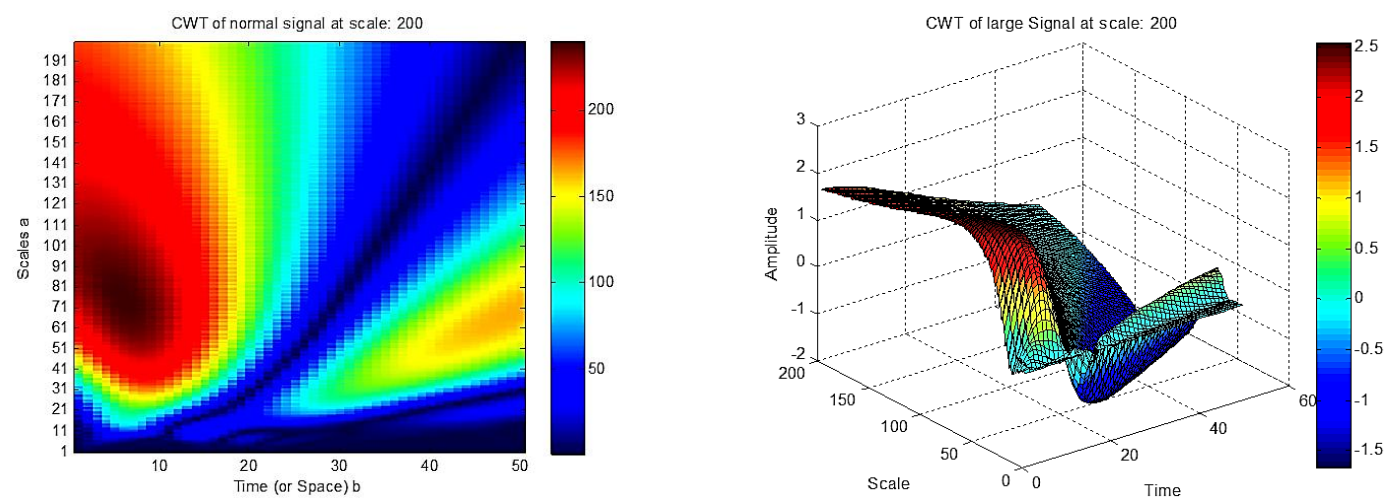

(b)
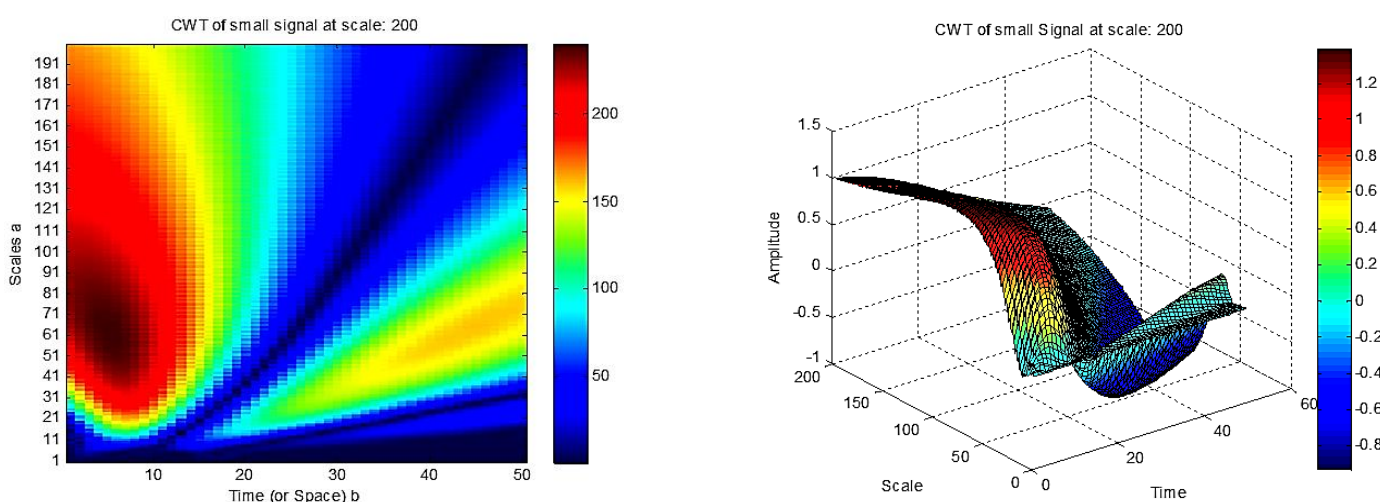

(c)
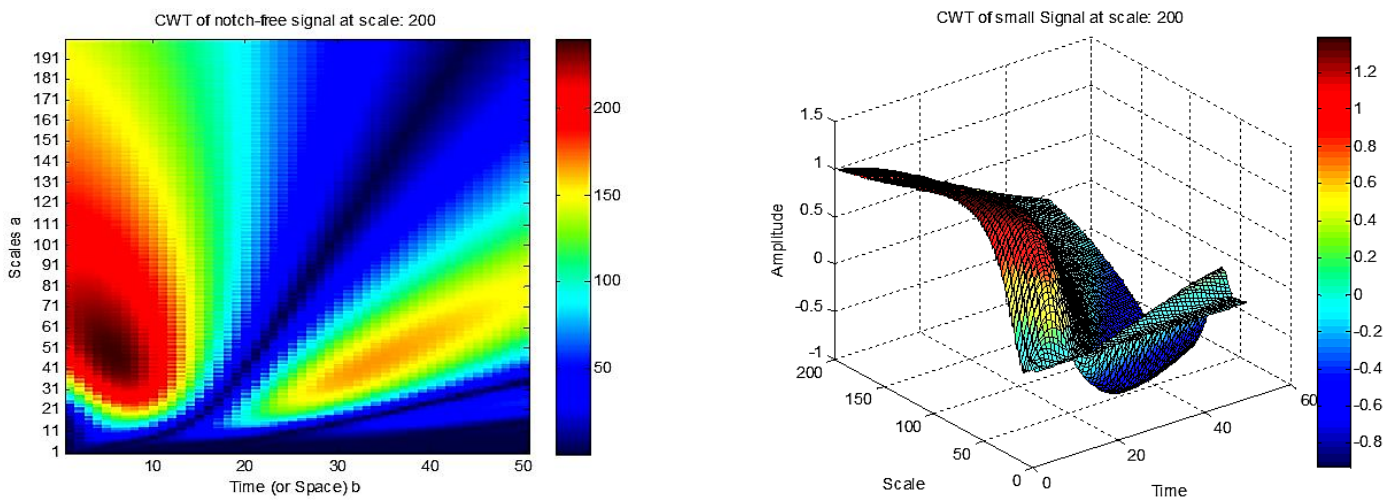

(d)
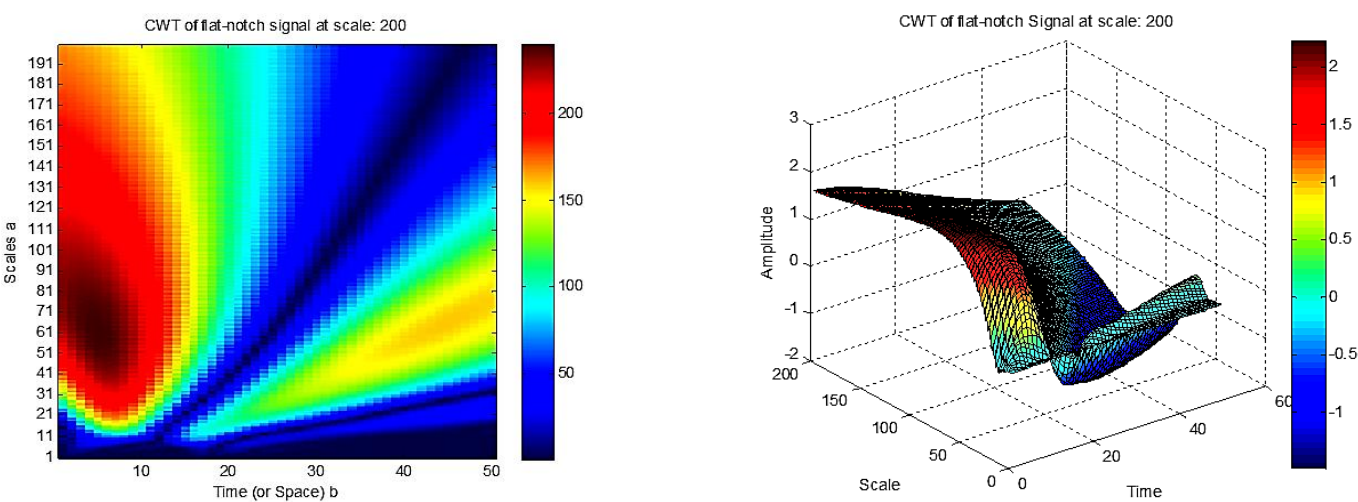

(e)

Figure 8. Contour plots (left sub-figures) and 3D surface plot (right sub-figures), (a) Normal CAPW signal, (b) CAPW with large and bounding pulses, (c) CAPW with small and week pulses, (d) CAPW with free dicrotic notch, and (e) CAPW with flat dicrotic notch 


\section{REFERENCES}

[1] F. A. Mahomed, "The physiology and clinical use of the use of the sphygmograph," Medical Times Gazette, vol. 1, pp. 62-64, 1872.

[2] F. A. Mahomed, "The etiology of bright's disease and the prealbuminuric stage," Journal of the Royal Society of Medicine, vol. MCT-57, no. 1, pp. 197-228, Jan. 1874, doi: 10.1177/095952877405700118

[3] F. A. Mahomed, “On the sphygmographic evidence of arterio-capillary fibrosis," Trans Pathol Soc, vol. 28, pp. 394-397, 1877.

[4] C. Vlachopoulos, M. O'Rourke, and W. W. Nichols, McDonald's Blood Flow in Arteries. CRC Press, 2011.

[5] A. P. Avolio, M. Butlin, and A. Walsh, "Arterial blood pressure measurement and pulse wave analysis-their role in enhancing cardiovascular assessment," Physiological Measurement, vol. 31, no. 1, pp. R1-R47, Nov. 2010, doi: 10.1088/0967-3334/31/1/R01.

[6] V. J. Dzau, "Tissue angiotensin and pathobiology of vascular disease a unifying hypothesis," Hypertension, vol. 37, no. 4, pp. 1047-1052, Apr. 2001, doi: 10.1161/01.HYP.37.4.1047.

[7] M. Wehling, "Preface," in Principles of Translational Science in Medicine: From Bench to Bedside: Second Edition, Elsevier, 2015, p. xiii.

[8] C. M. McEniery, J. R. Cockcroft, M. J. Roman, S. S. Franklin, and I. B. Wilkinson, "Central blood pressure: Current evidence and clinical importance," European Heart Journal, vol. 35, no. 26, pp. 1719-1725, Jan. 2014, doi: 10.1093/eurheartj/eht565.

[9] Y. Y. Lin Wang, T. L. Hsu, M. Y. Jan, and W. K. Wang, "Review: Theory and applications of the harmonic analysis of arterial pressure pulse waves," Journal of Medical and Biological Engineering, vol. 30, no. 3, pp. 125-131, 2010.

[10] R. R. Townsend et al. " "Clinical use of pulse wave analysis: proceedings from a symposium sponsored by North American Artery," Journal of Clinical Hypertension, vol. 17, no. 7, pp. 503-513, May 2015, doi: 10.1111/jch.12574.

[11] P. M. Nilsson and C. M. McEniery, "Early vascular aging in the young," in Early Vascular Aging (EVA), Elsevier, 2015, pp. $129-136$.

[12] J. Amar, J. B. Ruidavets, B. Chamontin, L. Drouet, and J. Ferrières, "Arterial stiffness and cardiovascular risk factors in a population-based study," Journal of Hypertension, vol. 19, no. 3, pp. 381-387, Mar. 2001, doi: 10.1097/00004872-20010300000005 .

[13] M. F. O’Rourke and A. P. X. J. Jiang, "Pulse wave analysis," British Journal of Clinical Pharmacology, vol. 51, no. 6, pp. 507-522, Jun. 2001, doi: 10.1046/j.0306-5251.2001.01400.x.

[14] D. A. McDonald, Blood flow in arteries. London: Edward Arnold Ltd., 1960.

[15] J. Womersley, The mathematical analysis of the arterial circulation in a state of oscillatory motion., no. 56. Wright Air Development Center Technical Report WADC-TR, 1957.

[16] L. Khadra, M. Matalgah, B. El-Asir, and S. Mawagdeh, "The wavelet transform and its applications to phonocardiogram signal analysis," Informatics for Health and Social Care, vol. 16, no. 3, pp. 271-277, Jan. 1991, doi: 10.3109/14639239109025301.

[17] M. Matalgah and J. Knopp, "Time-varying spectral analysis of non-stationary signals based on combined wavelet and fourier transforms," International Journal of Electronics, vol. 78, no. 3, pp. 463-476, Mar. 1995, doi: 10.1080/00207219508926177.

[18] A. Achmamad and A. Jbari, "A comparative study of wavelet families for electromyography signal classification based on discrete wavelet transform," Bulletin of Electrical Engineering and Informatics (BEEI), vol. 9, no. 4, pp. 1420-1429, Aug. 2020, doi: 10.11591/eei.v9i4.2381.

[19] N. Salankar, S. B. Nemade, and V. P. Gaikwad, "Classification of seizure and seizure free EEG signals using optimal mother wavelet and relative power," Indonesian Journal of Electrical Engineering and Computer Science (IJEECS), vol. 20, no. 1, pp. 197-205, Oct. 2020, doi: 10.11591/ijeecs.v20.i1.pp197-205.

[20] S. Sarkar, A. K. Bhoi, and G. Savita, "Fingertip pulse wave (PPG signal) analysis and heart rate detection," International Journal of Emerging Technology and Advanced Engineering, vol. 2, no. 9, pp. 404-408, 2012

[21] M. Sifuzzaman, M. Islam, and M. Ali, "Application of wavelet transform and its advantages compared to fourier transform," $J$. Phys. Sci, vol. 13, pp. 121-134, 2009.

[22] J. N. Cohn et al., "Noninvasive pulse wave analysis for the early detection of vascular disease," Hypertension, vol. 26, no. 3, pp. 503-508, Sep. 1995, doi: 10.1161/01.HYP.26.3.503.

[23] I. Bargiotas et al., "Estimation of aortic pulse wave transit time in MRI using complex wavelet cross-spectrum analysis," in Computing in Cardiology, Sep. 2015, vol. 42, pp. 725-728, doi: 10.1109/CIC.2015.7411013.

[24] Rafael C. Gonzalez and Richard E. Wood, Digital Image Processing, vol. 11, no. 1991. 2007.

[25] I. Daubechies, Ten Lectures on Wavelets. Society for Industrial and Applied Mathematics, 1992.

[26] S. G. Mallat, "A theory for multiresolution signal decomposition: the wavelet representation," IEEE Transactions on Pattern Analysis and Machine Intelligence, vol. 11, no. 7, pp. 674-693, Jul. 1989, doi: 10.1109/34.192463.

[27] Y. Meyer, Ondelettes et Opérateurs Tome 1, Hermann Ed.; English translation. Wavelets and Operators, 1993.

[28] R. C. Gonzalez, R. E. Woods, and S. L. Eddins, "Digital image processing using MATLAB ${ }^{2}$," 2nd edition, Gatesmark Publishing, 2009.

[29] T. N. Nguyen, T. H. Nguyen, and V. T. Ngo, "Artifact elimination in ECG signal using wavelet transform," Telkomnika (Telecommunication Computing Electronics and Control), vol. 18, no. 2, pp. 936-944, Apr. 2020, doi: 10.12928/TELKOMNIKA.V18I2.14403.

[30] M. Matalgah and J. Knopp, "Improved noise stability multiresolution filters based on a class of wavelets," in Midwest Symposium on Circuits and Systems, 1994, vol. 2, pp. 817-820, doi: 10.1109/mwscas.1994.518939.

[31] S. El-Sharo, "An attempt to develop a novel systemic technique for the evaluation of cardiovascular system," Medical Practice and Reviews, vol. 2, no. 1, pp. 1-10, 2011.

[32] H. Lax and A. W. Feinberg, "Abnormalities of the arterial pulse wave in young diabetic subjects.," Circulation, vol. 20, no. 6, pp. 1106-1110, Dec. 1959, doi: 10.1161/01.CIR.20.6.1106. 